\title{
Scenarios for RDF utilisation: reuse in technological plants or energy production
}

\author{
G. Genon \& E. Brizio \\ Politecnico di Torino, Italy
}

\begin{abstract}
It is possible to obtain a fraction of high calorific value, indicated as RDF (residue-derived-fuel) from municipal solid wastes using conventional separation systems. Two different solutions can be considered for utilisation; that is the use in technological plants (mainly cement kilns) or direct incineration. These two alternatives must be evaluated on the basis of the specific territorial situations and the RDF characteristics, taking into account different aspects:
\end{abstract}

- Local atmospheric pollution, as far as the removal capacity of the incinerators or pollutant formation in the cement kilns is concerned.

- The effect of the solution on greenhouse gas generation, taking into account fuel scenarios and emission trading procedures.

- Economics of substitution and planning perspectives.

Some general considerations about these aspects are derived from the results of real plants, and a specific application in the north of Italy has been considered; some positive aspects of co-incineration were identified, an important substitution capacity and limited atmospheric impact effects.

Keywords: RDF production, co-incineration, cement kiln, atmospheric impact, cost, planning.

\section{Introduction}

Within the choice of the correct final destination of solid urban wastes, that of energetic valorisation seems to be one of the most interesting options, given the vast choice of final destinations for this flux of material. On the other hand, it involves a heavy debate on the acceptability and compatibility of the 
technological solutions that are involved; in particular from the point of view of the atmospheric impact.

The present day tendency of planning, with particular reference to the Italian situation, is that of separating a combustible fraction from the waste material; the characteristics of this material are precisely defined. Starting from these considerations, there has been a widespread development of urban waste pre-treatment plants in Italy, which, once operating, produce an important flow of so-called RDF (residue-derived-fuel). As far as selection plants finalised to the production of RDF are concerned, the Italian Environmental Protection Agency (APAT) reports a treatment capacity of more than 7,5 $10^{6} \mathrm{t} / \mathrm{y} \mathrm{MSW}$ in Italy [1].

The fundamental point from which different indications arise and which is the subject of substantial ambiguity concerning all the technological development, is whether the RDF that is produced should be sent to specifically constructed plants in order to obtain thermal energy that in turn will be transformed into electricity for the energy market, or that the RDF should be utilised as a substitutive fuel material in technological plants, that is to say, in already existing plants with remarkable energy consumption capacity. Cement manufacturing plants are of significant importance for this latter proposal if we take into consideration their potentiality and high temperature conditions which seem to offer a suitable guarantee for thermal destruction, at least in principle.

Once RDF has been produced, it is necessary to compare both options and this should be done on the basis of a series of environmental compatibility and economic and planning prospective criteria that should obviously be evaluated case by case, taking into consideration the local context and the potentialities at play. In the present study, some indications are given to help orientate the choice, taking into consideration both what the European and non-European technological situation suggests and some particular experience gained in the Italian territory.

\section{Combustion of RDF in fluidised bed}

One of the possible destinations of RDF produced through different technologies, is that of combustion in fluidised bed kilns. This solution offers remarkable advantages over conventional combustion in grid furnaces. The advantages can thus be summarised:

- Thermal homogeneity and therefore high destruction of organic substances and, consequently, low content of organics in final slag.

- Limited formation of Nox.

- High energetic efficiency due to the limited excess of air.

- The possibility of carrying out corrective interventions on the quality of fumes directly on the inside of the fluidised bed.

- Combustion in homogeneous and controlled conditions

On the other hand, this solution has relatively high costs and proposes serious qualitative problems for the supplied material to burn; problems which are however resolved in the case of a correct production of RDF. 
From the point of view of performance, a detailed analysis of some commercial systems at present in use for combustion, which are specifically realised as fluidised bed systems, is shown in reference [2].

As far as the territory in the north of Italy is concerned, it is important to mention the operation of two important plants: the first one [3] has a potentiality of $200.000 \mathrm{t} / \mathrm{y}$ (the thermal capacity is around $67 \mathrm{MWt}$, delivers a net electric power of $15,5 \mathrm{MWe}$ ), with an electric production of $120 \mathrm{GWh} / \mathrm{y}$. The plant, which has been operating since 2000 , is at present being expanded; Table 1 illustrates the performance relative to the emissions.

Table 1: Emission concentrations registered for an Italian fluidised bed plant.

\begin{tabular}{|c|c|c|c|c|c|c|}
\hline & $\mathrm{HCl}$ & $\mathrm{CO}$ & NOx & $\mathrm{SO}_{2}$ & VOC & dust \\
\hline $\begin{array}{l}\text { Average of } 2600 \text { hourly } \\
\text { values }\left(\mathrm{mg} / \mathrm{Nm}^{3}\right)\end{array}$ & 6,4 & 16,2 & 154,7 & 0,5 & 0,5 & 1,6 \\
\hline $99^{\circ}$ percentile $\left(\mathrm{mg} / \mathrm{Nm}^{3}\right)$ & 18,9 & 85,6 & 208,7 & 3,2 & 2,0 & 5,2 \\
\hline
\end{tabular}

Another plant [4] deals with $60.000 \mathrm{t} / \mathrm{y}$ of RDF, has a thermal potentiality of $31 \mathrm{MWt}$, and an electric potentiality of $9 \mathrm{MWe}$. The plant has been operating since 2005 .

\section{The utilisation of RDF as fuel material in cement kilns}

An alternative to the aforementioned scenario is the development of systems that utilise RDF in cement kilns; these plants have a remarkable energy requirement (consider the use of 3000 up to $5000 \mathrm{~kJ} / \mathrm{kg}$ of produced clinker [5]) and, given the high temperatures at play, in principle they would seem ideal for the thermal destruction of residuals without causing impact conditions.

The operative scheme of a kiln is given in Figure 1 [6]. It can be seen how, in this case, the feed can in part be delivered to the head of the kiln, from which the clinker exits, with the fuel and fumes in a counter-current movement with respects to the movement of the material to be burned, and also delivered in part to the pre-calcinator, with different fume residence time and temperature conditions. In the first feed option, the fumes in fact have a permanence in the kiln of some tens of seconds and they cross zones where the temperature is higher than $1500^{\circ} \mathrm{C}$; in the second case, there are values of $800-900^{\circ} \mathrm{C}$ in the introduction zone and the permanence times of the fumes in the thermal recovery zone (with gradually decreasing temperatures) do not exceed but a few seconds. This obviously has important consequences on the possible reactions in the gas phase.

As far as the emissions into the atmosphere are concerned for this system, it is not easy to distinguish between the contribution of the clinker production process, and the contribution of the fuel RDF; it is in fact on this aspect that attention should be concentrated. 
As far as the aspect concerning the generic emission of combustion substances from cement kilns is concerned, some indications concerning the main products of combustion $\left(\mathrm{CO}_{2}, \mathrm{CO}\right.$, powders, $\left.\mathrm{NOx}, \mathrm{SO}_{2}\right)$ have been reported in the BREF documents [5].

As for the specific contribution of waste combustion, this can be well represented by the possible aspect of the formation of dioxins, which can derive from specific precursors present to a significant degree in the combustible. The possible presence of dioxins in fumes from cement kilns is reported [7] with dioxin emission factors in the range between 0,05 and $5 \mathrm{ng} \mathrm{I}-\mathrm{TEQ} / \mathrm{t}$ of produced cement (the typical value is $0,15 \mathrm{ng} \mathrm{I}-\mathrm{TEQ} / \mathrm{t}$ ). Moreover, the Inventory of Sources of Dioxins in the United States [8] details that $153 \mathrm{~g} \mathrm{I-TEQ} \mathrm{of} \mathrm{PCDD/F}$ were emitted in the year 1995 by cement kilns burning hazardous waste, whereas the emission of $17,8 \mathrm{~g}$ I-TEQ of PCDD/F per year is estimated for kilns burning non hazardous waste.

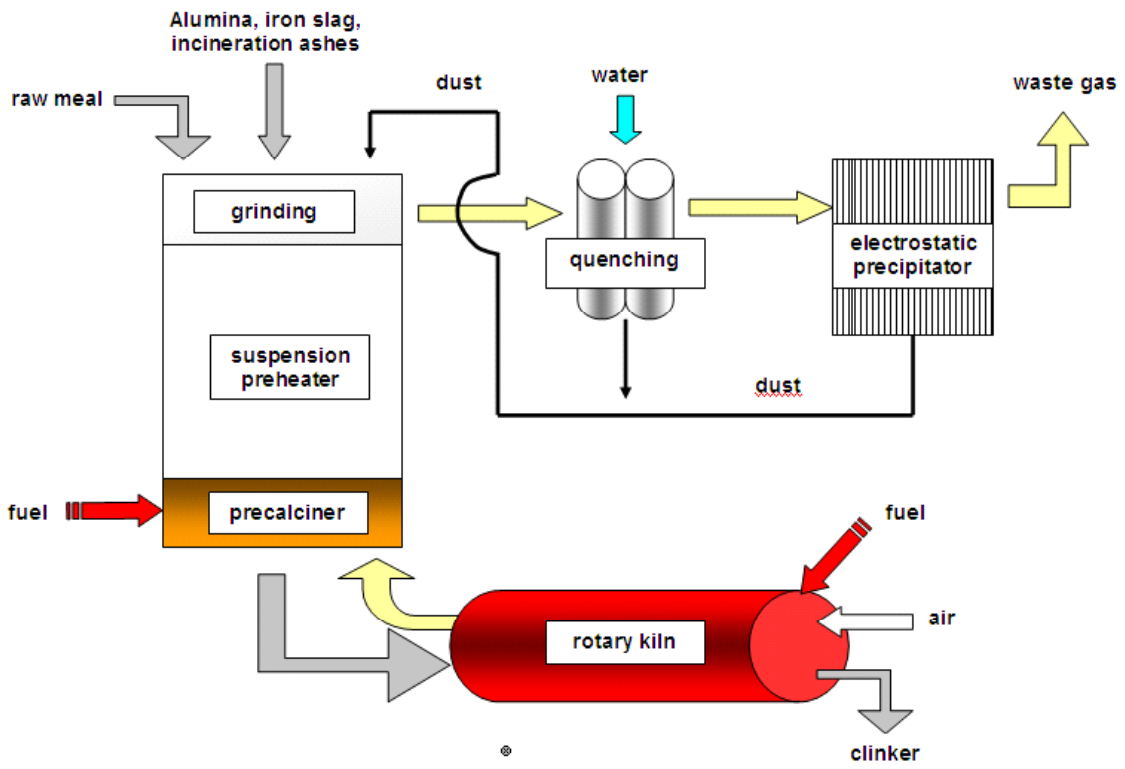

Figure 1: Diagram of a cement kiln with pre-heater and pre-calciner.

In the province of Cuneo (N.W. Italy), significant experience was gained through a collaboration between the Pirelli Ambiente society, the BUZZI UNICEM-Robilante cement manufacturer and the Waste Disposal Company in Cuneo [9]. A total of $25.000 \mathrm{t} / \mathrm{y}$ of material known as RDF-P (calorific power $>$ $4.500 \mathrm{kcal} / \mathrm{kg}$, moisture $<10 \%$, total chlorine $<0,5 \%$, PCB-PCT $<5 \mathrm{ppm}, \mathrm{PAH}$ $<5$ ppm, $\mathrm{Cd}<100$ ppm, $\mathrm{Hg}<10$ ppm, $\mathrm{Zn}<5000$ ppm, $\mathrm{Pb}<2000$ ppm, etc) is produced from urban waste gathered in the city of Cuneo, after mixing with plastic and rubber residuals. 


\section{Local and global effects for the two layouts}

The alternative between RDF combustion in a specifically set up plant or the use of a cement kiln, should consider as a first element of evaluation, the effect of the different final destinations on the emission of the pollutants and therefore on the environmental compatibility. For this purpose, two types of evaluation should be distinguished, the global aspect, from the point of view of greenhouse gases and therefore in particular of $\mathrm{CO}_{2}$ emissions, and the local or regional aspect, connected to the emission of macro-pollutants $\left(\mathrm{NO}_{\mathrm{x}}, \mathrm{HCl}, \mathrm{PM}\right)$ and micro-pollutants (PCDD/F, heavy metals) and therefore of environmental compatibility in terms of induced toxicity.

Table 2: $\quad$ Results of impact assessment of 4 technical options for burning $1 \mathrm{Mg}$ RDF.

\begin{tabular}{|c|c|c|c|c|c|c|c|c|c|}
\hline & & $\begin{array}{c}\text { Brown Coa } \\
\text { RDF }\end{array}$ & $\begin{array}{l}\text { fired Power Plant } \\
\text { Subst. fuel } \\
\text { (brown coal) }\end{array}$ & $\begin{array}{l}\text { Hand Coal } \\
\text { RDF }\end{array}$ & $\begin{array}{l}\text { red Power Plant } \\
\text { subst. fuel } \\
\text { (hard coal) }\end{array}$ & $\begin{array}{l}\text { Ceme } \\
\text { RDF }\end{array}$ & $\begin{array}{l}\text { Work } \\
\text { subst. fuel } \\
\text { (hard coal) }\end{array}$ & RDF & $\begin{array}{l}\text { sSW } \\
\text { subst. } \\
\text { electricity mix }\end{array}$ \\
\hline \multicolumn{10}{|c|}{ Fossil Resources } \\
\hline Raw oil & $\mathrm{kg}$ & $5.03 E+00$ & $1.22 \mathrm{E}+00$ & $5.22 \mathrm{E}+00$ & $5.80 \mathrm{E}+00$ & $2.17 E+01$ & $2.28 \mathrm{E}+01$ & $4.64 E+00$ & $7.80 \mathrm{E}-01$ \\
\hline Natural Gas & $\mathrm{kg}$ & $3.60 E+00$ & $3.17 E+00$ & $4.33 E+00$ & $1.16 E+00$ & $8.34 E+\infty 0$ & $5.50 E+00$ & $4.14 \mathrm{E}+00$ & $1.13 E+01$ \\
\hline Hard coal & $\mathrm{kg}$ & $2.15 E+01$ & $1.69 \mathrm{E}+00$ & $2.14 E+01$ & $5.70 \mathrm{E}+02$ & $3.70 \mathrm{E}+01$ & $5.84 E+02$ & $2.16 E+01$ & $4.70 \mathrm{E}+01$ \\
\hline Brown coal & $\mathrm{kg}$ & $6.40 E+01$ & 1.33E+03 & $6.32 E+01$ & $5.09 E+00$ & $1.05 E+02$ & 5.38E+01 & $7.04 E+01$ & $1.78 E+02$ \\
\hline Total (CED) & kJ , & $1.88 E+06$ & $1.78 E+07$ & $1.74 E+06$ & $1.62 E+07$ & $3.17 E+06$ & $1.78 E+07$ & $2.10 E+06$ & $3.36 \mathrm{E}+06$ \\
\hline \multicolumn{10}{|c|}{ Global Warming } \\
\hline $\mathrm{CO}_{2}$ (fossil) & $\mathrm{kg}$ & 4.75E+02 & $1.71 \mathrm{E}+03$ & $4.72 E+02$ & $1.47 \mathrm{E}+03$ & $2.46 E+03$ & $3.93 E+03$ & $4.79 \mathrm{E}+02$ & $3.29 E+02$ \\
\hline $\mathrm{CH}_{4}$ & $\mathrm{~kg}$ & 3.27E-01 & $2.48 \mathrm{E}-02$ & $3.31 E-01$ & $6.89 E+00$ & $7.46 \mathrm{E}-01$ & $7.41 \mathrm{E}+00$ & $3.28 \mathrm{E}-01$ & $6.41 E-01$ \\
\hline $\mathrm{N}_{2} \mathrm{O}$ & $\mathrm{kg}$ & $1.15 \mathrm{E}-02$ & $5.08 \mathrm{E}-02$ & $3.82 E-02$. & 2.98E-02 & $1.53 E-02$ & $1.01 \mathrm{E}-02$ & $1.44 \mathrm{E}-02$ & 4.18E-03 \\
\hline GWP & $\mathrm{kg} \mathrm{CO}_{2}$-Eq & $4.85 E+02$ & $1.72 E+03$ & $4.91 E+02$ & $1.62 E+03$ & $2.48 E+03$ & $4.09 E+03$ & $4.91 E+02$ & $3.44 E+02$ \\
\hline \multicolumn{10}{|c|}{ Summer Smog } \\
\hline $\mathrm{CH}_{4}$ & $\mathrm{~kg}$ & $3.27 \mathrm{E}-01$ & $2.48 E-02$ & 3.31E-01 & $6.89 E+00$ & 7.46E-01 & $7.41 E+00$ & 3.28E-01 & $6.41 E-01$ \\
\hline NMVOC & $\mathrm{kg}$ & 3.67E-01 & $6.17 E-02$ & 3.67E-01 & $6.33 E-02$ & $3.63 E-01$ & $6.08 \mathrm{E}-02$ & 3.17E-01 & $1.07 E-02$ \\
\hline Nox & $\mathrm{kg}$ & $1.24 E+00$ & $1.24 E+00$ & $1.14 E+00$ & $1.18 E+00$ & $6.85 E+00$ & $7.21 E+00$ & $1.11 E+00$ & 4.69E-01 \\
\hline NCPOCP & $\mathrm{kg}$ & $4.22 E-01$ & $1.79 E-01$ & $4.05 E-01$ & 2.97E-01 & $1.03 E+00$ & $7.89 E-01$ & 3.69E-01 & $6.47 E-02$ \\
\hline \multicolumn{10}{|l|}{ Acidification } \\
\hline $\mathrm{SO}_{2}$ & $\mathrm{~kg}$ & $6.38 \mathrm{E}-01$ & 1.37E+00 & $1.01 E+00$ & $1.47 E+00$ & $1.01 E+00$ & $1.00 E+00$ & 6.19E-01 & 2.55E-01 \\
\hline Nox & $\mathrm{kg}$ & $1.24 E+00$ & $1.24 E+00$ & $1.14 E+00$ & $1.18 E+00$ & $6.85 E+00$ & $7.21 \mathrm{E}+00$ & 1.11E+00 & 4.69E-01 \\
\hline $\mathrm{NH}_{3}$ & $\mathrm{~kg}$ & $2.06 E-01$ & $1.76 E-01$ & $1.04 E-01$ & $4.44 E-02$ & $6.16 \mathrm{E}-02$ & $9.55 \mathrm{E}-04$ & $7.82 \mathrm{E}-02$ & $2.95 \mathrm{E}-03$ \\
\hline $\mathrm{HCl}$ & $\mathrm{Kg}$ & $3.82 \mathrm{E}-01$ & 8.75E-01 & 4.27E-01 & 7.52E-02 & $3.36 \mathrm{E}-02$ & 2.05E-02 & 2.89E-02 & $1.06 \mathrm{E}-02$ \\
\hline $\mathrm{HF}$ & $\mathrm{kg}$ & $2.68 \mathrm{E}-03$ & 5.94E-03 & $2.68 \mathrm{E}-03$ & 2.41E-03 & $4.51 \mathrm{E}-03$ & 2.46E-03 & 4.92E-03 & $1.50 \mathrm{E}-03$ \\
\hline
\end{tabular}

As far as the global aspect is concerned, it is interesting to observe what has been reported in Table 2 [1], which illustrates the contribution deriving from the utilisation of a unit of RDF supplied to a cement kiln, or to a combustion system for energetic purposes, to global warming, to photochemical smog, to acidification and to the consumption of resources. It should be noted that the result takes into consideration the different steps of use of the RDF, from the production to the utilisation. One thing that appears to be particularly significant is the data relative to $\mathrm{CO}_{2}$ emissions, which basically appears to be the most important parameter as far as the contribution to the system is concerned, with respect to the Kyoto parameters. The use of RDF in cement manufacturing kilns seems to be positive as the combustion of RDF allows a reduction of about 1.61 $\mathrm{kg}$ of $\mathrm{CO}_{2}$ per $\mathrm{kg}$ of utilised RDF compared to conventional combustible materials (coal), due to the chemical composition of the combustible material. In the case of utilisation in specifically set up combustion systems with energetic recovery, taking into consideration what the energetic mix for the production of 
electric energy is and the efficiency of the electric production, the substitution of the combustible material involves an increase in production of $\mathrm{CO}_{2}$ of about $0.15 \mathrm{~kg}$ per $\mathrm{kg}$ of RDF.

As far as the impact that derives from the emission of atmospheric pollutants from the raw composition of the burned RDF is concerned, the problem consists in the possible transfer of the substances contained in the waste towards the atmosphere or the produced clinker, while in the case of incineration, the possible transfer is towards either the atmospheric flow or residuals from the treatment of the fumes.

A possible contamination of fuels derived from urban waste, the transfer coefficients in the case of specific incineration (data from 23 waste incineration plants in Germany, Switzerland, the Netherlands and Austria) and those relative to the use in cement kilns are shown in Table 3 [10,11].

If we observe the compared figures, it can be noted that there are clearly higher chlorine and sulphur releases into the atmosphere of chlorine in the case of co-combustion, as well as the heavy metals retention capacity of the treatment systems for incineration appears to be much higher than those seen in co-combustion systems. In the case of incineration, the complementary quantity of the emitted substance is therefore retained and incorporated in a matrix that constitutes a hazardous residual which is then destined to specific inactivation treatments, while in the case of co-combustion the transfer occurs towards the clinker, with less guarantee of non transfer into the environment later on.

Table 3: Transfer factors to waste gas for RDF contaminants, in the case of incineration and co-combustion in cement kilns.

\begin{tabular}{|c|c|c|c|}
\hline \multirow{4}{*}{ Parameter } & $\begin{array}{c}\text { Substitute fuel } \\
\text { from domestic } \\
\text { wastes (mg/Mg) }\end{array}$ & $\begin{array}{c}\text { Transfer factors } \\
\text { to waste gas for } \\
\text { incinerators }\end{array}$ & $\begin{array}{c}\text { Transfer factors to } \\
\text { waste gas for } \\
\text { cement kilns }\end{array}$ \\
\hline Chlorine & 3.710 .300 & 0,0008 & 0,034 \\
\cline { 2 - 4 } $\begin{array}{c}\text { Sulphur } \\
\text { Cadmium }\end{array}$ & 1.402 .500 & 0,001 & 0,031 \\
\cline { 2 - 4 } Thallium & 2.600 & 0,005 & 0,01873 \\
\cline { 2 - 4 } $\begin{array}{c}\text { Mercury } \\
\text { Antimony }\end{array}$ & No data & 0,00065 & 0,00875 \\
\cline { 2 - 4 } Arsenic & 300 & 0,05 & 0,49 \\
\cline { 2 - 4 } $\begin{array}{c}\text { Lead } \\
\text { Chromium } \\
\text { Cobalt }\end{array}$ & 14.300 & 0,00004 & 0,00042 \\
\cline { 2 - 4 } Copper & 900 & 0,00001 & 0,00020 \\
\cline { 2 - 4 } Manganese & 102.500 & 0,00005 & 0,01015 \\
\cline { 2 - 4 } Nickel & 11.300 & 0,00005 & 0,00018 \\
\cline { 2 - 4 } Vanadium & 600 & 0,00005 & 0,00040 \\
\cline { 2 - 4 } & 45.000 & 0,00005 & 0,00010 \\
\hline Tin & 52.500 & 0,00005 & 0,00019 \\
\cline { 2 - 4 } Zinc & 1.500 & 0,00005 & 0,00050 \\
\cline { 2 - 4 } & 300 & 0,00005 & 0,00437 \\
\hline
\end{tabular}


A complete study has been conducted on the dioxin emissions from the cocombustion system [12]. The main indications there contained are as follows: there is no correlation between dioxin emissions and the type of alternative combustible material used (Figure 2):

- The formation of dioxins can occur in a thermal window between 200 and $450^{\circ} \mathrm{C}$, zones that are encountered in fume cooling systems before the final separator of the fumes.

- Potential precursors released by combustible material introduced into the pre-calcination zone can react with the chlorine not retained by the alkaline matrix of the clinker, in the presence of metallic catalysts present in the transported powders, giving rise to emissions of dioxin where de-novo synthesis occurs.

- While the dioxin concentrations are, in most cases, lower than $0.1 \mathrm{ng} / \mathrm{Nm}^{3}$, concentrations of PCB at least a thousand times higher are possible and they, in this sense, constitute a significant source of precursors that are able to generate micro-pollutants where the aforementioned kinetic conditions allow this to happen.

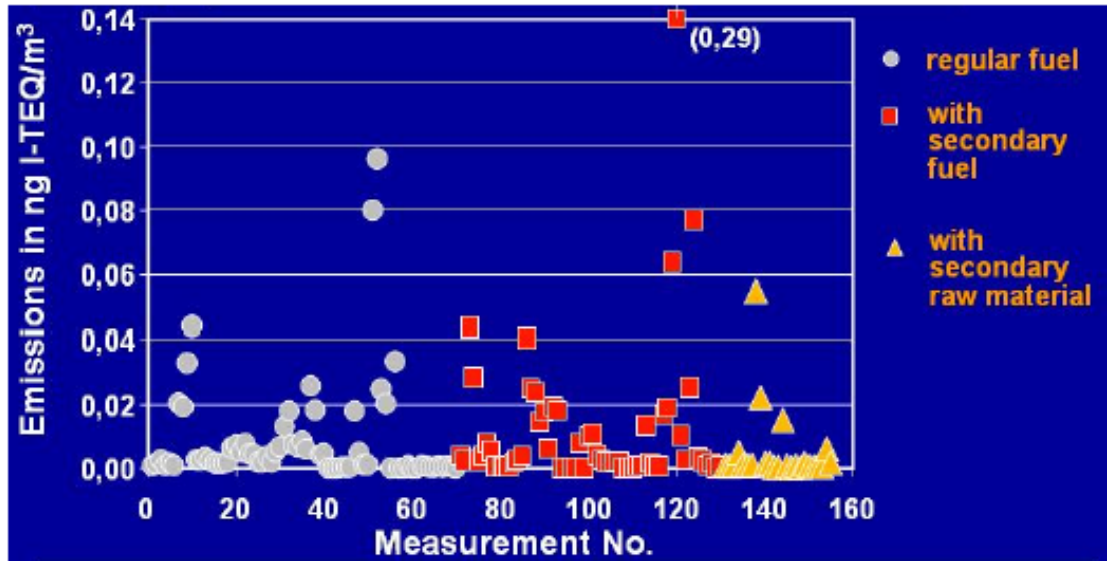

Figure 2: $\quad$ PCDD/F emissions of German cement kilns between 1999 and 2002.

Faced with this situation, the incineration systems at present in use are normally endowed with active carbon removal systems, which are able to control and keep the emissions at levels well below $0.1 \mathrm{ng} / \mathrm{Nm}^{3}[13,14]$.

A final consideration should be made concerning micro-pollutants. It would certainly be more opportune to talk about mass fluxes rather than emission concentrations. In fact, in an incineration system, the combustion of $1 \mathrm{~kg}$ of RDF produces $5 \mathrm{Nm}^{3}$ of fumes, with a $\mathrm{PCDD} / \mathrm{F}$ concentration lower than $0.1 \mathrm{ng} / \mathrm{Nm}^{3}$, that is a specific emission of $0,5 \mathrm{ng} \mathrm{PCDD} / \mathrm{F} / \mathrm{kg} \mathrm{RDF}$; on the other hand, in a cement kiln, considering a substitution rate of the combustible of $20 \%$ by wastes, $30 \mathrm{~g}$ of supplied RDF produce an emission of $3 \mathrm{Nm}^{3}$ of fumes with a 
PCDD/F concentration below $0.1 \mathrm{ng} / \mathrm{Nm}^{3}$, that is a specific emission of $10 \mathrm{ng}$ $\mathrm{PCDD} / \mathrm{F} / \mathrm{kg}$ RDF. Obviously, it is not possible to say that all the possible dioxins derive from the RDF, but if we admit that this is true, the specific generation capacity of the co-combustion systems in cement kilns would be decidedly higher.

\section{Economics aspects and planning}

Apart from the impact point of view, comparison between the solution of disposal in incinerators or in co-combustion systems should also be considered from the operational cost point of view. As far as the utilisation of specifically set up systems is concerned, a sufficiently complete list of costs is reported for different European countries [15]. The reported costs are clearly different according to the considered context, and they depend on various factors, such as:

- The logistical position, cost of ground and transport costs.

- The dimensioning of the plant and its rate of utilisation.

- The standards required for atmospheric emissions and the necessity of treating residuals.

- Returns from the assignment of thermal or electric energy.

- Taxes on incineration or easy terms in the generation of energy.

These topics should be considered in each different local situation, but it is certainly possible to identify a realistic industrial cost into which externality considerations could be inserted, taking into account the considerations of the previous section.

Specific construction and manufacturing costs, operating and maintenance (O\&M) costs for fluidised bed plants operating on RDF are given in Table 4 [2].

Table 4: $\quad$ Investment and operating costs for fluidised bed plants.

\begin{tabular}{|c|c|c|c|c|c|}
\hline Location & Capacity & $\begin{array}{l}\text { Investment } \\
\text { costs }\end{array}$ & $\begin{array}{c}\text { Specific } \\
\text { investment } \\
(\$ /(t / y))\end{array}$ & $\begin{array}{c}\text { O\&M } \\
\text { costs } \\
(\mathrm{M} \$ / \mathrm{y})\end{array}$ & $\begin{array}{c}\text { Specific } \\
\text { O\&M } \\
\text { costs }(\$ / t)\end{array}$ \\
\hline Robbins (Ill) & $1450 \mathrm{t} / \mathrm{d}$ & $226 \mathrm{M \$}$ & 550 & 15,8 & 29 \\
\hline Lidkoping (Sw) & $\begin{array}{c}70.000 \\
t / y\end{array}$ & $\begin{array}{c}104 \text { MSEK } \\
(1984)\end{array}$ & 163 & 4,27 & 61 \\
\hline Toshima (Jp) & $400 \mathrm{t} / \mathrm{d}$ & $140 \mathrm{M} \$$ & 960 & - & 127 \\
\hline $\begin{array}{l}\text { Madrid TIR } \\
\text { (Sp) }\end{array}$ & $\begin{array}{c}260.000 \\
t / y\end{array}$ & $125 \mathrm{MS}$ & 480 & 13,5 & 51,9 \\
\hline $\begin{array}{c}\text { Dundee DERL } \\
\text { (Scotland) }\end{array}$ & $\begin{array}{c}120.000 \\
t / y\end{array}$ & $56 \mathrm{M} \$$ & 466 & 3,7 & 31 \\
\hline Valene (F) & $3 \times 3,4 \mathrm{t} / \mathrm{h}$ & $50 \mathrm{M} \$$ & 570 & 10 & 125 \\
\hline
\end{tabular}

As far as combustion in cement kilns is concerned, the costs have to be defined case by case, taking into account the following items:

- The ratio of calorific power of the substituted combustible to the RDF.

- The market cost of the substituted fuel. 
- The difference between the operational cost of the kiln in a conventional set up or using of RDF.

- The cost or entrance taxes for the substituting fuel.

As far as these items are concerned, the constant increase in costs of the combustible market, the possible acquisition in importance of emission trading derived from the application of the Kyoto protocol, the greater plant treatment and maintenance costs which a substitutive combustible involves, the competition of other potentially combustible residuals, the costs avoided due to the different destinations of the RDF and the policies for the incentives related to renewable energy sources should all be taken into account.

Another aspect that is of fundamental importance is that of the planning prospective and the facility of utilizing the RDF. As far as this is concerned, it is necessary to consider the potentiality of the installed cement production plants and of their RDF acceptance capacity. As an example of the Italian territory, there are about 60 plants and 80 kilns for the production of cement [16] which accounts for over $40 \times 10^{6} \mathrm{t}$ /year. If we assume a specific energy consumption of $4 \times 10^{3} \mathrm{~kJ} / \mathrm{kg}$ in clinker production kilns, and a calorific power of the RDF of $15 \times 10^{3} \mathrm{~kJ} / \mathrm{kg}$, about $107 \times 10^{3} \mathrm{t} /$ year of RDF can be supplied to cement plants for each percentage point of caloric substitution. The contribution to the disposal and valorisation of wastes, using a technology involving very few transformations already available on the territory, is immediately obvious.

On the other hand, the construction of specifically set up plants certainly requires long periods for the identification of the sites, political decisions and the construction and starting up of the plant; this way is certainly more penalised than the immediate prospective.

It is also essential to take into account the constrain that the prospective of a supply contract of RDF imposes on the producer or public holder of this type of material concerning its final use, the possible competition of other types of alternative combustible materials on the market and potential local reactions to the alteration of a production plant to a plant involved in the disposal of urban waste.

These aspects must be evaluated case by case taking into consideration the dimensions of the problem, the local industrial structure, the energy market and the suitability of the solutions.

\section{A local case in Piedmont}

As already seen, an interesting study has been undertaken in the Piedmont region, in terms of the use of substitutive combustible materials and coincineration. The substitution was carried out in two kilns in the plant, one with a capacity of $145 \mathrm{t} / \mathrm{h}$ of clinker and the other one with a capacity of $79 \mathrm{t} / \mathrm{h}$. The caloric substitution was around 7,5\% and 1\% respectively in 2004 . The highest possible energetic substitution was $40 \%$ in the kiln (Temperature $>1450^{\circ} \mathrm{C}$, excess air in the range 1,10-1,15, retention time much higher than $2 \mathrm{~s}$ ) and $50 \%$ in the precalciner (Temperature $>850^{\circ} \mathrm{C}$, excess air in the range $1,10-1,15$, retention time $>2 \mathrm{~s}$ ). If we compare the emissions of the third kiln of the same 
cement factory, where only coal is used as the combustible material, with those of the other two kilns, where an important quantity of alternative combustible materials is used, one could easily notice that the co-incineration practice does not seem to affect the quality of the emissions, at least from the point of view of macro-pollutants (NOx, SOx, VOC, CO, dust).

\section{Conclusions}

The examination carried out in this paper has shown a comparison between the conventional disposal of RDF and the use of co-incineration systems, and the following aspects have emerged:

- Environmental criteria: for co-incineration systems advantages from the greenhouse gas point of view and some negative indications from the critical point of view of micro-pollutants.

- Economic criteria: dependence of the co-incineration on the market situations, costs that depend on the energy market and the disposal of the residuals for combustion.

- Planning criteria: availability of a potentiality for co-incineration systems, the necessity of political agreement and not very short periods for incineration systems.

Finally, these criteria can constitute a reference framework, with respects to which, a politically significant and programming decision must be made for each individual local situation.

\section{References}

[1] APAT - Rapporto Rifiuti 2004 - December 2004

[2] Technoeconomic Assessment of Fluidised Bed Combustors as MSW incinerators: a Survey of six Case Studies - IEA Bioenergy Task 36

[3] A. Fara, F. Gasparini, I. Vitali - Termovalorizzazione energetica di RSU: l'esperienza operativa di Lomellina Energia

[4] Corso di aggiornamento Energia da Rifiuti Politecnico di Milano, 2005 Impianto ECODECO di Corteolona (Pv)

[5] EU - IPPC Reference Document on Best Available Techniques in the Cement and Lime Manufacturing Industries - Dec. 2001

[6] G. Bargagli - L'esperienza Holcim nella combustione di RDF nei forni da cemento

[7] EU - Compilation of EU Dioxin Exposure and Health Data - Oct. 1999

[8] EPA Environmental Inventory of Sources of Dioxin in the USA - April 1998

[9] Informazione Tecnica Pirelli Idea Granda

[10] EEB BZL Ecodumping by Energy Recovery - Jan. 2001

[11] LCA IWM - The use of LCA Tool for the Development of Integrated Waste Management Strategies for Cities and Regions with Rapid Growing Economies - August 2005 
[12] SINTEF - Formation and Release of POP in the Cement Industries - 2004

[13] EU Reference Document on Best available Techniques for Waste Incineration - July 2005

[14] Air Pollution Control Technology in Japan - Toxic Substance removal technology

[15] Eunomia Ecotec - Costs for Municipal Waste Management in the EU

[16] Linee Guida per l'individuazione e l'utilizzazione delle migliori tecniche disponibili - Produzione di cemento - gennaio 2004 